Review

\title{
Recognizing Dissolved Organic Matter with an Improved Fluorescence Regional Integral Method
}

\author{
${ }^{1}$ Zhang Jianguo, ${ }^{2,3, *}$ Wang Xinyi, ${ }^{2}$ Liu Xiaoman, ${ }^{2}$ Li Jianlin, ${ }^{1}$ Guo Jianwei and ${ }^{1}$ Zhang Bo \\ ${ }^{1}$ Institute of Energy and Chemical Industry, China Pingmei Shenma Group, Pingdingshan 467000, China \\ ${ }^{2}$ Institute of Resources and Environment, Henan Polytechnic University, Jiaozuo 454000, China \\ ${ }^{3}$ Collaborative Innovation Center of Coalbed Methane and Shale Gas for Central Plains Economic Region, \\ Henan Province, Jiaozuo 454000, China
}

\section{Article history}

Received: 09-10-2019

Revised: 05-12-2019

Accepted: 20-12-2019

Corresponding Author:

Wang Xinyi

Institute of Resources and

Environment, Henan

Polytechnic University, Jiaozuo

454000, China;

Collaborative Innovation

Center of Coalbed Methane and

Shale Gas for Central Plains

Economic Region, Henan

Province, Jiaozuo 454000,

China

Email: zwwfhh321@126.com

\begin{abstract}
The aim of this paper was to study transformations of Dissolved Organic Matter (DOM) in marl rock groundwater. To achieve this, we carried out a series of soil column experiments, using a DOM solution as the water sample and marl rock as the testing rock sample. Three-Dimensional Excitation-Emission Matrix Spectra (3DEEMS) were generated for DOM solutions and the Analytic Hierarchy Process (AHP) was introduced to improve the traditional method of fluorescence regional integral (TMFRI). We termed this approach the Improved Method of Fluorescence Regional Integral (IMFRI) and used it to identify the type of DOM in the marl rock. The result shows that DOM recognition using TMFRI is only 50\% accurate and consequently transformations are hard to recognize. In contrast, our results show that use of IFRIM has a DOM type recognition accuracy of $83.33 \%$ and so this method can be used with confidence to describe transformation characteristics. And we find that in the marl rock, the leaching test showed a new fluorescence peak at $312 \mathrm{~h}$ and the humic acid was degraded into soluble microbial products by microorganisms.
\end{abstract}

Keywords: DOM, 3DEEMS, AHP, TMFRI, IMFRI, Marl Rock

\section{Introduction}

Dissolved Organic Matter (DOM) is an important solute in groundwater. These solutions commonly comprise a mixture of aliphatic and aromatic organic compounds that include oxygen, nitrogen and sulfur functional groups. DOM is usually defined as an organic matter that can pass through a membrane filter with a $0.45 \mu \mathrm{m}$ aperture size (Leenheer and Croué, 2003; Buffle and Leppard, 1995). DOM includes tyrosine, tryptophan fulvic acid, metabolite from soluble microorganisms, humic acid substances, etc. Since there is absorption, exchange and complexation between the functional groups in DOM and the ions in the environment (Maximiliano et al., 2009), research in this area has been both a focus and area of contention in international hydro geochemistry.

Research on DOM was initiated from the late eighteenth century (Ghabbour and Davies 2001). Pallo, for example, divided humic acid and fulvic acid into different components and developed a method to subdivide the former into soluble and non-soluble components (Waksman 1938). Waksman introduced the theory of lignin protein and demonstrated its importance in nature (Pollo, 1993). Much later, Christman and Gjessing (1983) presented a definition for aquatic humic acid as opposed to its terrestrial counterpart. Zhou et al. (2010; Porcal and Kopáček, 2018; Zhou et al., 2019; Johs et al., 2019; Li et al., 2018), have done many studies on the role of transformation and migration that DOM has on polycyclic aromatic hydrocarbons, phosphorus, copper ions, mercury and cadmium.

With the appearance of three-Dimensional Excitation- Emission Matrix Spectra (3DEEMS), the study of DOM has gone a step further. The core principle of this method involves generating a 3DEEMS image by sending fluorescence spectra intensity at given excitation and emission wavelengths on a plane as abscissa that ordinate with one another in order to distinguish different kinds of DOM (Coble et al., 1990). Cui et al. (2016) researched the constitution and features of resolvable matters in the Baiyangdian District through 3DEEMS. He et al. (2015) researched the origin and constitution of resolvable organic matter in the groundwater polluted by leachate using 3DEEMS in tandem with chemical analysis. Zhu et al. (2010) conducted research on the effect of the oxidation- 
reduction condition on 3DEEMS of DOM in water and found that humid acid matter is easy to degrade in oxidation environments.

The Traditional Method of Fluorescence Regional Integral (TMFRI) has most often been utilized to determine the amount of fluorescence in different DOM partitions based on integrals from 3DEEMS. Applying the TMFRI can greatly enhance analyses based on 3DEEMS both qualitatively to quantificationly. Zhao et al. (2013) examined the fluorescence characteristics of fulvic acid in the sediment in Xingkai Lake using the TMFRI. Jiang et al. (2015) used the same approach to present a quantitative evaluation of the effects of DOM removal from different plants. Lei et al. (2015) quantitatively characterized the DOM of natural soil using a three-Dimensional (3D) matrix in combination with the TMFRI method. However, because TMFRI does not include the location of the peak appearance of 3DEEMS, the quantitative result is quite different from reality. It has therefore proved problematic to precisely describe changes in DOM using this approach.

Based on a dynamic leaching modeling experiment with marl rock distilled on the scene, this essay quantitatively analyzes the DOM features of leach ate using the combinative Analytic Hierarchy Process (Wang et al., 2017) (AHP) as well as 3DEEMS TMFRI. We expect that a reasonable confirmation of weight can be achieved to describe the transformation regularity of DOM, contributing to the mechanism study of ground water recharge, runoff and discharge in loose aquifers.

\section{Materials and Methodology}

\section{Testing Samples}

In Pingdingshan coalfield, underground water in the Cambrian limestone aquifer is the main threat to coal seam mining. Most of the shallow buried Cambrian limestone is covered by Neogene marl rock. Precipitation and surface water supply to the aquifer limestone percolates through the marl. The permeation characteristics of the marl rock obtained in Pingdingshan coalfield are studied in this paper.

The sampling depth of the marl rock is $15 \mathrm{~m}$ and its physical properties are presented in Table 1. We used a self-confected DOM solution, with an original concentration of $70.9 \mathrm{mg} / \mathrm{L}$, was chosen as the infiltration solution.

\section{Experimental Devices}

The simulated experimental column used in this experiment had a height of $50 \mathrm{~cm}$ and internal diameter of $7 \mathrm{~cm}$. This column was placed inside the thermostat, as shown in Fig. 1, with the injection port and sampling port positioned at the top and bottom of the column, respectively, connected to each other via a rubber hose.
Leachate was provided by a stable fluid supply device composed of a high position bucket and a peristaltic pump.

Marl samples were placed into the column alongside coarse grain quartz sand, with a particle size of $3 \mathrm{~cm}$, which was placed at both ends of the column to distribute the leachate smoothly and keep its homogeneous flow. DOM quality concentration was calculated in terms of Chemical Oxygen Demand measured by potassium dichromate, mg/L (CODcr), while a titration test was held following disinfection through a WMX-III microwave device. 3DEEMS detection is carried out by a Fluorescence Spectrophotometer (HITACHI F-7000, Tokyo, Japan) and the data are processed through Software Origin and characterized by the intensity contour on the fluorescence spectrum. The 3DEEMS of the origin DOM solution is shown in Fig. 2.

Table 1: Basic physical and chemical properties of the marl rock samples

\begin{tabular}{llll}
\hline Name & $\begin{array}{l}\text { Sampling } \\
\text { depth }(\mathrm{m})\end{array}$ & $\begin{array}{l}\text { Natural bulk } \\
\text { density }\left(\mathrm{g} / \mathrm{cm}^{3}\right)\end{array}$ & $\begin{array}{l}\text { Porosity } \\
(\%)\end{array}$ \\
\hline Marl rock & 15 & 1.47 & 23 \\
\hline
\end{tabular}

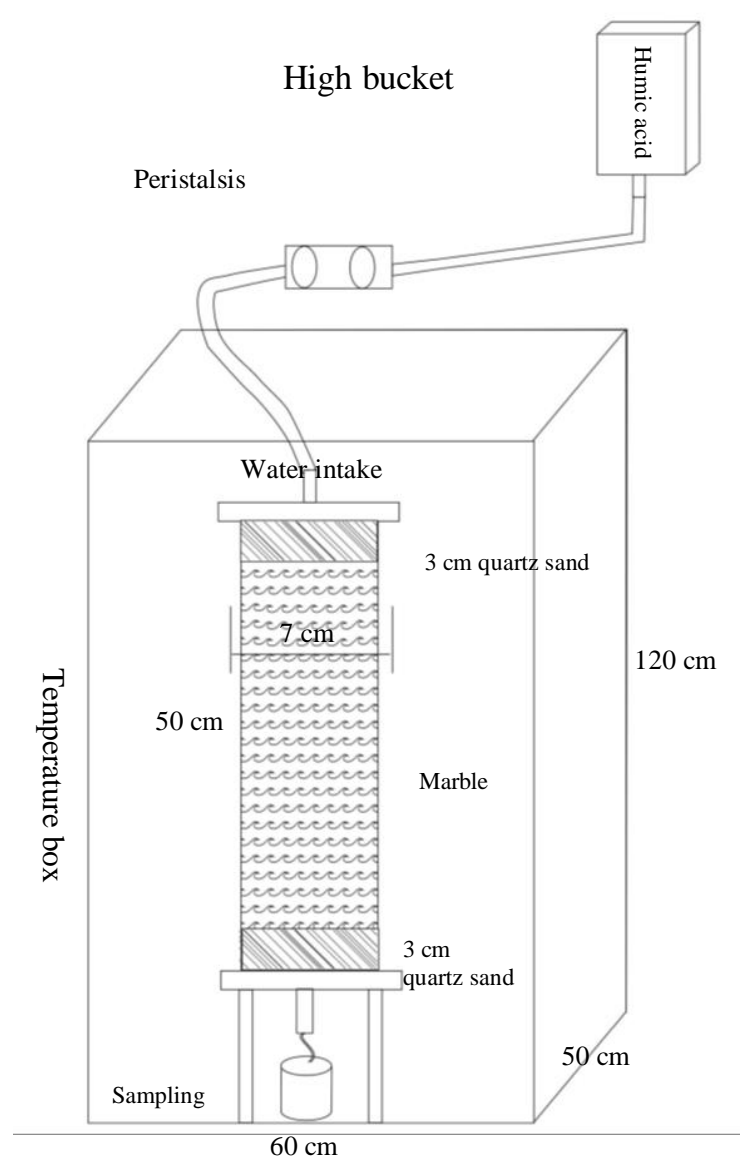

Fig. 1: The experimental setup used in this study 


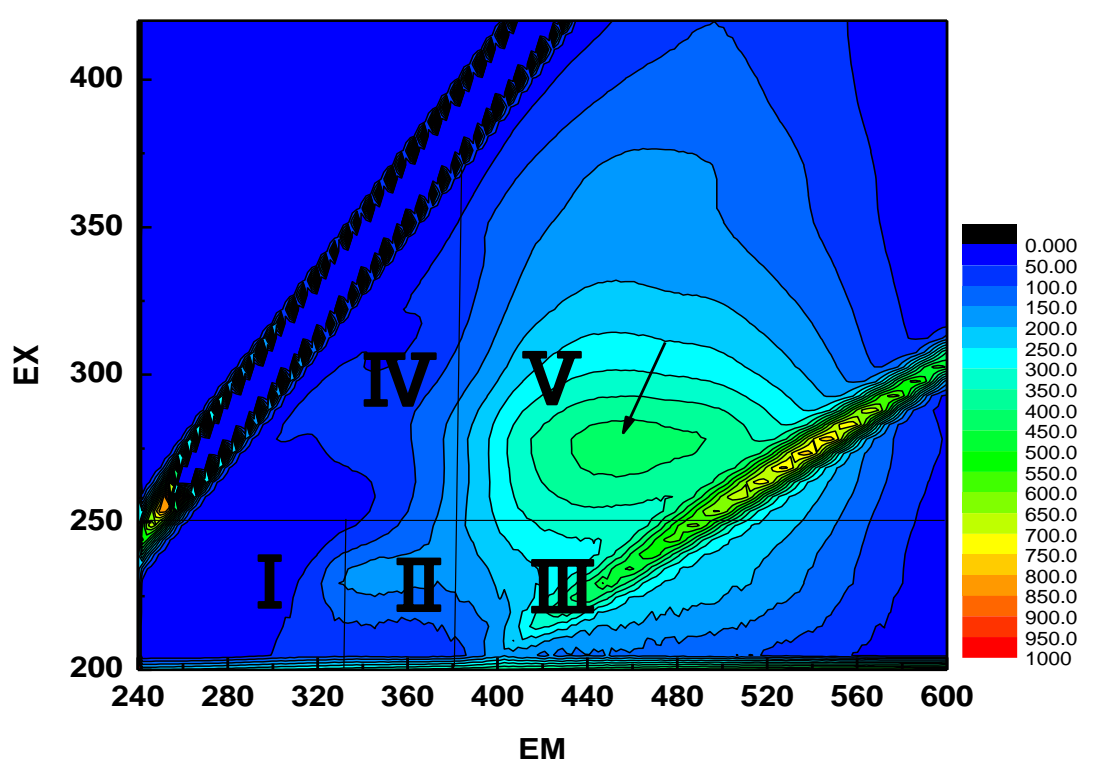

Fig. 2: Original DOM leachate used for 3DEEManalysis

\section{Experimental method}

Under room temperature $\left(25^{\circ} \mathrm{C}\right)$ conditions, distilled water was pumped into the bottom of the soil column to expel the gas and prevent any penetrative effect on the rock sample. DOM solution at a concentration of $70.9 \mathrm{mg} / \mathrm{L}$ was then pumped into the rock column at $2.5 \mathrm{ml} / \mathrm{h}$ and fluid was removed from the bottom of the column. We then measured the 3DEEM and plotted the spectral intensity contours.

\section{Improved Fluorescence Regional Integral}

\section{Traditional Method of Fluorescence Regional Integral (TMFRI)}

Chen et al. (2003), as well as other researchers, divided the 3DEEMS into five sections, Fluorescence peaks fall in different areas to represent different substances as shown in Fig. 3. For example, When Fluorescence peaks fall in Region I symbolizing tryptophan. Regional boundaries are as follows: Region I: $\mathrm{EX} \leq 250 \mathrm{~nm}, \mathrm{EM}<330 \mathrm{~nm}$, symbolizing tyrosine; Region II: $\mathrm{EX} \leq 250 \mathrm{~nm}, 330 \mathrm{~nm} \leq \mathrm{E} \mathrm{M} \leq 380 \mathrm{~nm}$, symbolizing tryptophan; Region III: EX $\leq 250 \mathrm{~nm}, \mathrm{EM}>$ $380 \mathrm{~nm}$, symbolizing fulvic acid; Region IV: EX > 250 $\mathrm{nm}, \mathrm{EM} \leq 380 \mathrm{~nm}$, symbolizing soluble microbial metabolites; and Region V: EX > 250 nm, EM > 380 $\mathrm{nm}$, symbolizing humic acid substances.

TMFRI can be used to identify each of these five regions, as well as to calculate the regional integrals $\Phi_{i, n}$ of the 3DEEMS intensity in each region (He et al., 2011):

$$
\Phi_{i, n}=\int I(E X / E M) d\left(\lambda_{E X}\right) d\left(\lambda_{E M}\right)
$$

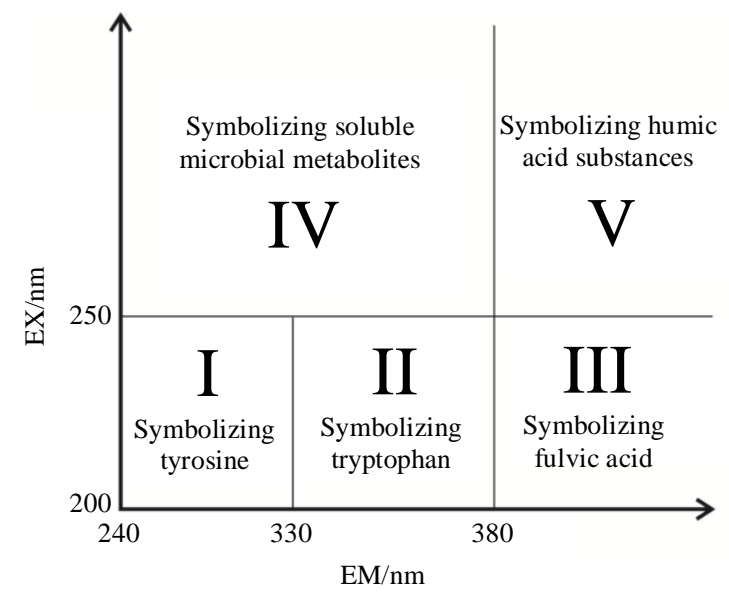

Fig. 3: Regional division of 3DEEMS

$I(E X / E M)$ is used to state the 3DEEMS intensity corresponding to the excitation-emission wavelength; $\lambda_{E X}$ and $\lambda_{E M}$ represent excitation wavelength and emission wavelength, respectively.

Integral proportion of the fluorescence spectra in each section can be calculated by the following two formulas:

$P_{i, n}=\frac{\Phi_{i, n}}{\Phi_{T, n}}$

$\Phi_{T, n}=\sum_{i=1}^{5} \Phi_{i, n}$

$\Phi_{i, n}$ is the fluorescence spectra quantity in each region (i.e., integral of fluorescence spectra intensity) 
and $\Phi_{T, n}$ is the summation of fluorescence spectra quantity in the five regions.

\section{Improved Method of Fluorescence Regional Integral (IMFRI)}

TMFRI makes use of the peak value and contour intensive degree of 3DEEMS to determine the integral value, which has the advantage of simple calculation (He et al., 2011). The identified DOM type is possibly different from the actual result as the TMFRI does not take the location of the peak value of the 3DEEMSand the effect among the five regions. Here, the AHP is introduced to confirm the weight and characterize the location of the peak value of the 3DEEMS. Formula 4 and formula 5 are used to calculate the fluorescence spectra quantity and integral proportion of fluorescence spectra:

$Q_{i, n}=W_{i} * \Phi_{i, n}$

$A_{i, n}=\frac{Q_{i, n}}{Q_{T, n}}$

$Q_{T, n}=\sum_{i=1}^{5} Q_{i, n}$

Among the three equations, $W_{i}$ is used to describe the weight of the 3DEEMS in each region. $\Phi_{i, n}$ states the fluorescence spectra quantity calculated in each region (see formula 1). $Q_{i, n}$ stands for the fluorescence spectra quantity in each section. $Q_{T, n}$ represents the total amount of the fluorescence spectra quantity. $A_{i, n}$ is the integral proportion of the fluorescence spectral in each region (\%).

As for a complex system, which is controlled by multi-factors and is hard to be accurate, here are the basic steps to make use of the AHP for analysis and evaluation: Confirm the affiliation among all factors, construct factor hierarchy and evaluate the factors in each hierarchy, introduce the optimal transfer matrix to construct the judgment matrix to calculate the corresponding influence coefficient of the factors in each hierarchy. This approach improves the judgment accuracy, leaving out consistency checking and increasing the operability after bringing in the optimal transfer matrix (Xu et al., 2007).

\section{The Weight Determination with IMFRI}

The experiment takes the DOM state as the example (Fig. 2), with a concentration of $70.9 \mathrm{mg} / \mathrm{L}$ and provides a statement of the IMFRI. According to the position of the peak value of the fluorescence spectra intensity and the fluorescence spectra quantity $\Phi_{i, n}$ calculated by the TMFRI, a judgment matrix to calculate the weight $W_{i}$ is built. The basic principle is that the region with peak value occurrence is more important than the one without it and the region with large $\Phi_{i, n}$ calculated by the TMFRI is more important than the one with small $\Phi_{i, n}$.

Construction judgment matrix A:

$$
A=\left[\begin{array}{ccccc}
0 & -1 & -1 & -1 & -1 \\
1 & 0 & 1 & 1 & -1 \\
1 & -1 & 0 & 1 & -1 \\
1 & -1 & -1 & 0 & -1 \\
1 & 1 & 1 & 1 & 0
\end{array}\right]
$$

where, $a_{i j}=1$ states that ' $i$ ' is more important than ' $j$ '; $a_{i j}=0$ states that ' $i$ ' is as important as ' $j$ '; $a_{i j}=-1$ states that ' $j$ ' is more important than ' $i$ '. $A$ 's optimal transfer matrix is $R$ :

$$
R=\left[\begin{array}{ccccc}
0 & -1.2 & -0.8 & -0.4 & -1.6 \\
1.2 & 0 & 0.4 & 0.8 & -0.4 \\
0.8 & -0.4 & 0 & 0.4 & -0.8 \\
0.4 & -0.8 & -0.4 & 0 & -1.2 \\
1.6 & 0.4 & 0.8 & 1.2 & 0
\end{array}\right]
$$

In which:

$r_{i j}=\frac{1}{n} \ddot{O}_{i, n} \sum_{k=1}^{n}\left(a_{i k}-a_{j k}\right)$

$=\frac{1}{n} \sum_{k=1}^{n}\left(a_{i k}-a_{k j}\right)$

The judgment matrix for $\mathrm{R}$ is matrix $\mathrm{D}$ :

$$
D=\left[\begin{array}{lllll}
1.00 & 0.30 & 1.45 & 0.67 & 0.20 \\
3.32 & 1.00 & 1.49 & 2.23 & 0.67 \\
2.23 & 0.67 & 1.00 & 1.49 & 0.45 \\
1.49 & 0.45 & 0.67 & 1.00 & 0.30 \\
4.95 & 1.49 & 2.23 & 3.32 & 1.00
\end{array}\right]
$$

In which:

$d_{i j}=\exp \left(r_{i j}\right)$

The weight of the 3DEEMS in each section is determined according to judgment matrix D:

$W=[0.08,0.26,0.17,0.11,0.38]$

In which:

$W=\frac{\sqrt[n]{\coprod_{k=1}^{n} d_{i j}}}{\sum_{k=1}^{n} \sqrt[n]{\coprod_{k=1}^{n} d_{i k}}}$ 


\section{Results and Arguments}

\section{Features of 3DEEMS}

We perform a leaching experiment on the DOM solution with a concentration of $70.9 \mathrm{mg} / \mathrm{L}$, extract the leaching solution at $0,48,192,240,312$ and $600 \mathrm{~h}$ and test the 3DEEMS of each sample, as shown in Fig. 4.

From Fig. 4, there are two fluorescence peaks at $0 \mathrm{~h}$, which are tryptophan (Region II: EX $=225 \mathrm{~nm}, \mathrm{EM}=$ $342 \mathrm{~nm}$ ) and soluble microbial metabolites (Region IV: $\mathrm{EX}=280 \mathrm{~nm}, \mathrm{EM}=345 \mathrm{~nm}$ ).

There are two fluorescence peaks at $48 \mathrm{~h}$, which are soluble microbial metabolites (Region IV: EX $=270 \mathrm{~nm}$, $\mathrm{EM}=340 \mathrm{~nm}$ ) and humic acids (Region V: $\mathrm{EX}=252$ $\mathrm{nm}, \mathrm{EM}=430 \mathrm{~nm}$ ).

There are two fluorescence peaks at $192 \mathrm{~h}$, which are soluble microbial metabolites (Region IV: EX $=278 \mathrm{~nm}$, $\mathrm{EM}=342 \mathrm{~nm}$ ) and humic acids (Region V: EX $=321$ $\mathrm{nm}, \mathrm{EM}=390 \mathrm{~nm}$ ).
There are two fluorescence peaks at $240 \mathrm{~h}$, which are tryptophan (Region II: EX $=244 \mathrm{~nm}, \mathrm{EM}=362 \mathrm{~nm}$ ) and soluble microbial metabolites (Region IV: EX $=283 \mathrm{~nm}$, $\mathrm{EM}=349 \mathrm{~nm}$ ).

There are three fluorescence peaks at $312 \mathrm{~h}$, which are a tryptophan fluorescence peak (Region II: EX $=242 \mathrm{~nm}$, $\mathrm{EM}=370 \mathrm{~nm})$ and two fluorescence peaks of soluble microbial metabolites (Region $\mathrm{IV}_{1}: \mathrm{EX}=281 \mathrm{~nm}, \mathrm{EM}=$ $354 \mathrm{~nm}$; Region $\mathrm{IV}_{2}$ : $\mathrm{EX}=275 \mathrm{~nm}, \mathrm{EM}=305 \mathrm{~nm}$ ).

At $600 \mathrm{~h}$, the location and type of fluorescence peaks are almost the same as those at $312 \mathrm{~h}$, which are a tryptophan fluorescence peak (Region II: EX $=241 \mathrm{~nm}$, $\mathrm{EM}=372 \mathrm{~nm}$ ) and two fluorescence peaks of soluble microbial metabolites $\left(\right.$ Region $\mathrm{IV}_{1}: \mathrm{EX}=280 \mathrm{~nm}, \mathrm{EM}=$ $355 \mathrm{~nm}$; Region $\mathrm{IV}_{2}$ : $\mathrm{EX}=273 \mathrm{~nm}, \mathrm{EM}=300 \mathrm{~nm}$ ).

\section{TMFRI Results}

We use TMFRI to do a quantitative calculation of the 3DEEMS. Table 2 shows the fluorescence spectra quantity and integral proportion.

Table 2: Three-dimensional fluorescence identification results using TMFRI

\begin{tabular}{llll}
\hline Time & Fluorescence spectra region & Fluorescence spectra quantity & Integral proportion (\%) \\
\hline $0 \mathrm{~h}$ & I & 95.05 & 2.95 \\
& II & 139.40 & 4.32 \\
& III & 836.40 & 25.92 \\
& IV & 1118.87 & 34.68 \\
Total & V & 1036.79 & 32.13 \\
$48 \mathrm{~h}$ & & 3226.51 & 100 \\
& I & 17.50 & 1.11 \\
& II & 448.82 & 28.45 \\
& III & 397.73 & 25.21 \\
& IV & 358.29 & 22.71 \\
Total & V & 355.38 & 22.52 \\
$192 \mathrm{~h}$ & & 1577.72 & 100 \\
& I & 16.55 & 1.19 \\
& II & 175.24 & 12.66 \\
& III & 385.16 & 27.83 \\
& IV & 397.20 & 28.70 \\
Total & V & 409.93 & 29.62 \\
$240 \mathrm{~h}$ & I & 1384.08 & 100 \\
& II & 173.81 & 8.26 \\
& III & 596.21 & 28.35 \\
& IV & 238.77 & 11.35 \\
Total & V & 636.97 & 30.29 \\
$312 \mathrm{~h}$ & & 457.44 & 21.75 \\
& I & 2103.20 & 100 \\
& II & 201.56 & 7.7 \\
& III & 707.02 & 26.99 \\
Total & IV & 345.95 & 13.21 \\
$600 \mathrm{~h}$ & V & 833.41 & 31.82 \\
& & 531.18 & 20.28 \\
& I & 2619.12 & 100 \\
& II & 1065.86 & 33.63 \\
& III & 506.37 & 15.98 \\
& IV & 196.50 & 6.19 \\
& V & 868.74 & 27.41 \\
& & 532.19 & 100 \\
\hline & & 3169.66 & \\
& & & 00 \\
& & & \\
& & &
\end{tabular}


Zhang Jianguo et al. / American Journal of Biochemistry and Biotechnology 2019, 15 (4): 241.250 DOI: 10.3844/ajbbsp.2019.241.250

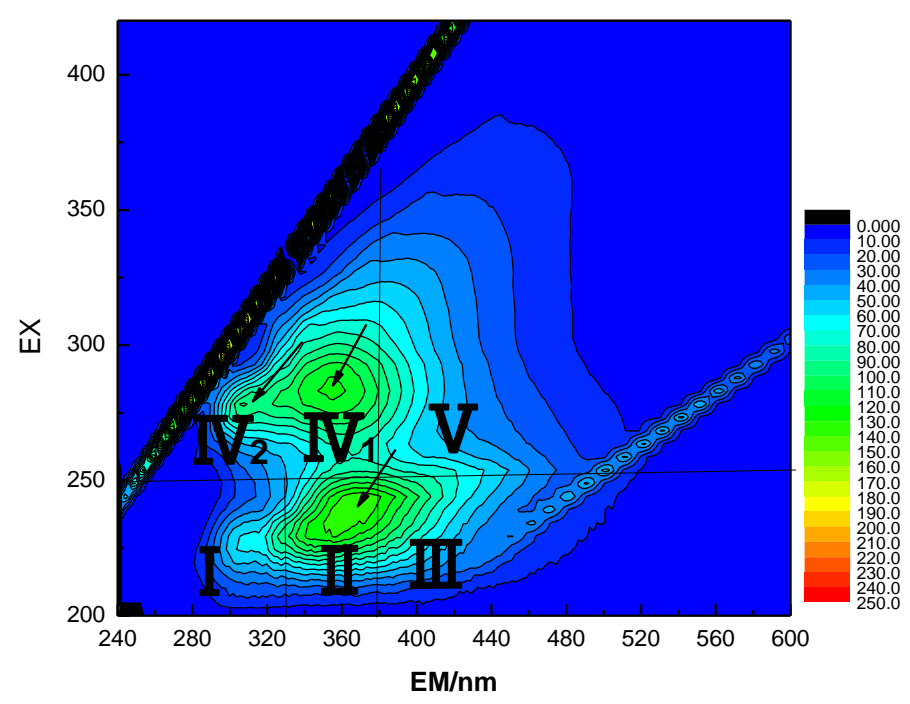

(a)

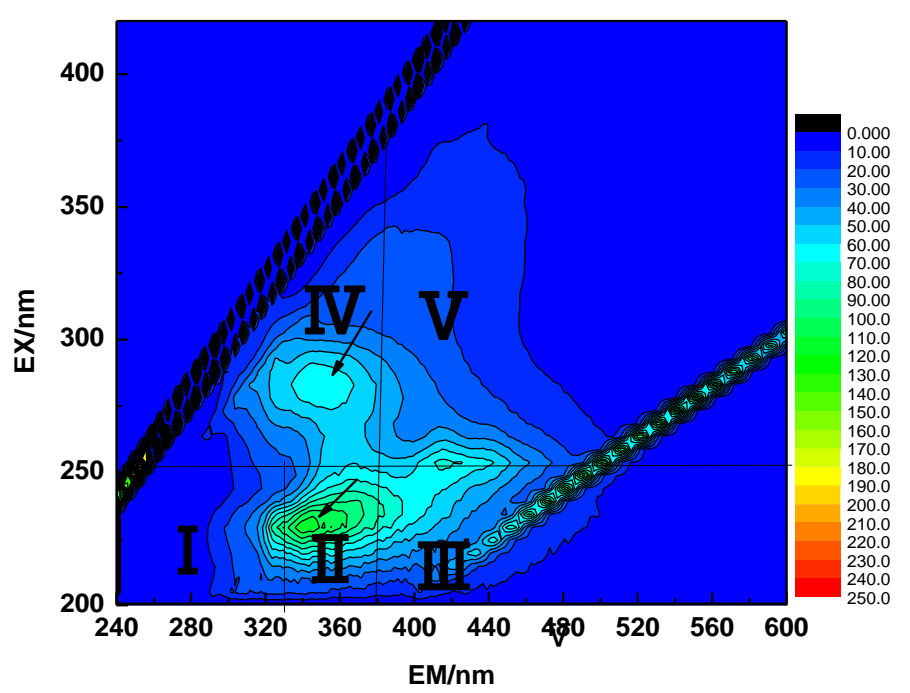

(b)

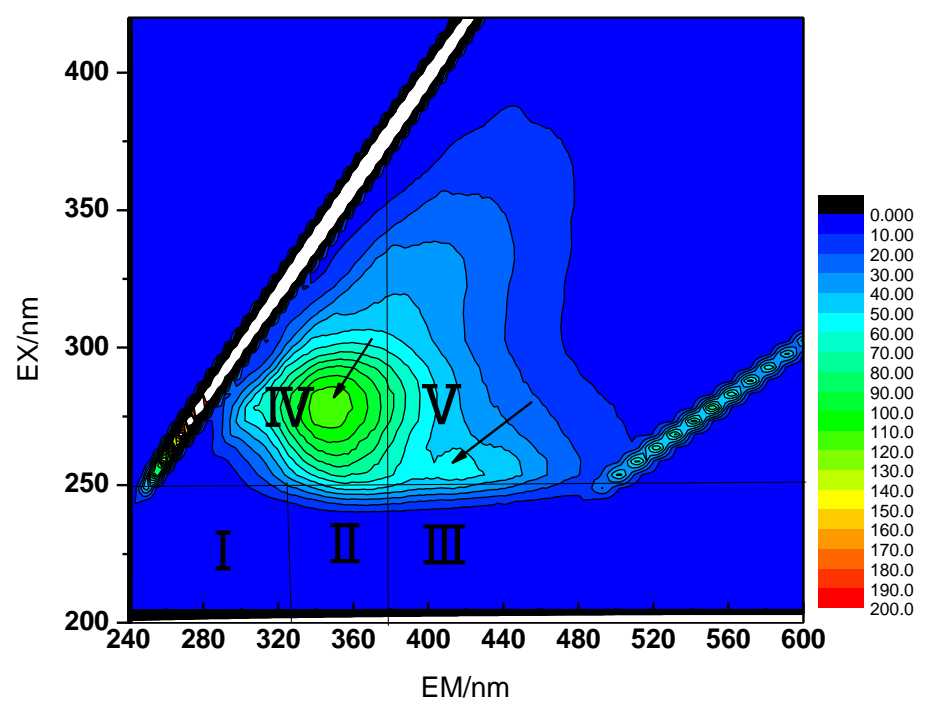

(c) 


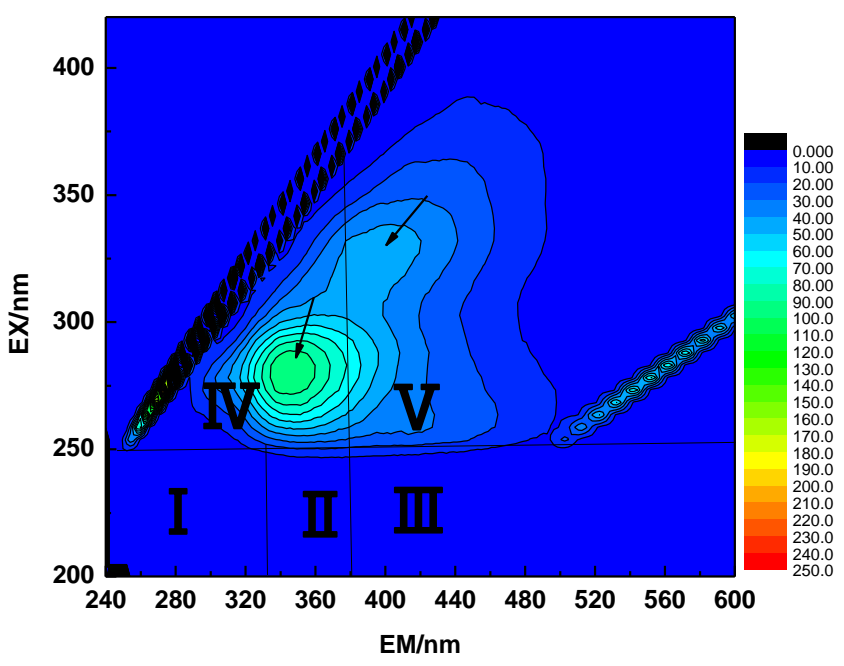

(d)

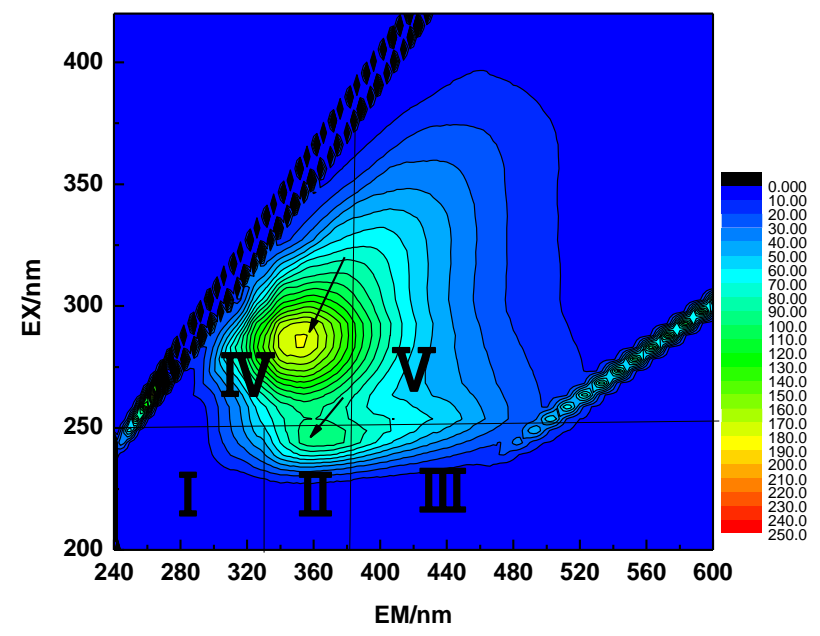

(e)

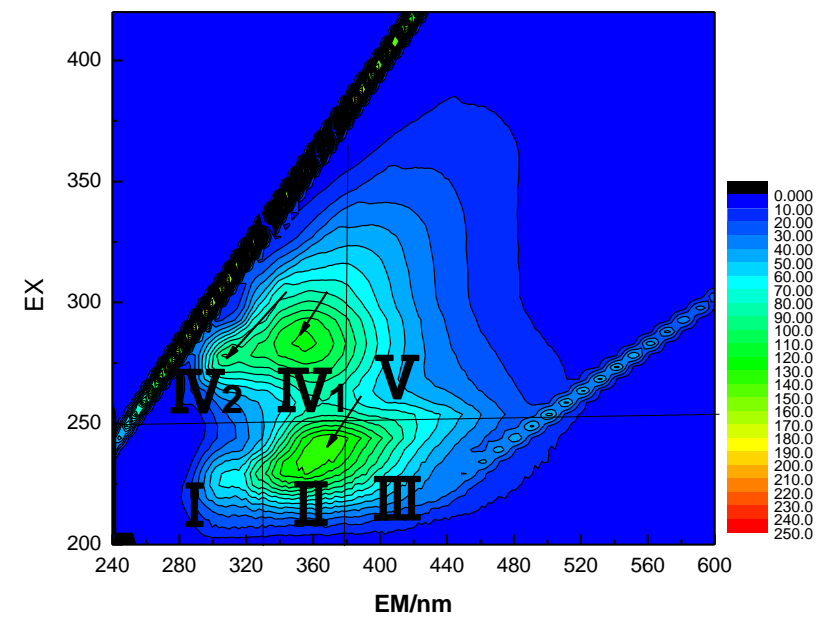

(f)

Fig. 4: 3DEEMS of leached liquid from marl rock; (a) 192 h; (b) 312 h; (c) 0 h; (d) 48 h; (e) 240 h; (f) 600 h 
From the calculated value of the integral proportion, through TMFRI, we know the main types of DOM (the two largest values of the integral proportion, the red color in Table 2) are as follows: Soluble microbial metabolites in Region IV and humic acids in Region $\mathrm{V}$ at $0 \mathrm{~h}$, tryptophan in Region II and fulvic acid in Region III at $48 \mathrm{~h}$, soluble microbial metabolites in Region IV and humic acids in Region Vat $192 \mathrm{~h}$, tryptophan in Region II and soluble microbial metabolites in Region IV at $240 \mathrm{~h}$ and $312 \mathrm{~h}$ and tyrosine in Region I and soluble microbial metabolites in Region IV at $600 \mathrm{~h}$.

\section{IMFRI Results}

According to the weight calculating steps of the DOM state in Section 2.3, we confirm the weight of DOM leachate at different times and its results are shown in Table 3. Based on the fluorescence spectra with the TMFRI (Table 2), we use the IMFRI to calculate the fluorescence spectra quantity and integral proportion with the results shown in Table 3.

Apparently, the main types recognized with IMFRI are shown as follows: At $0 \mathrm{~h}$, the main types are fulvic acid in Region III and soluble microbial metabolites in Region IV. At $48 \mathrm{~h}$ and $192 \mathrm{~h}$, the main types are soluble microbial products in Region IV and humic acid in Region V. At 240 h, 312 h and 600 h, the main types are tryptophan in Region II and soluble microbial metabolites in Region IV.

\section{Result Comparison}

The main types of DOM leaching liquid, which are based on the features of 3DEEMS, TMFRI and IMFRI, are listed in Table 4.

Table 3: Three-dimensional fluorescence identification results using IMFRI

\begin{tabular}{|c|c|c|c|c|c|}
\hline Time & $\begin{array}{l}\text { Fluorescence } \\
\text { spectra region }\end{array}$ & $\begin{array}{l}\text { Fluorescence spectra } \\
\text { quantity of TMFRI }\end{array}$ & Weight & $\begin{array}{l}\text { Fluorescence spectra } \\
\text { quantity of IMFRI }\end{array}$ & Integral proportion $(\%)$ \\
\hline \multirow[t]{5}{*}{$0 \mathrm{~h}$} & I & 95.05 & 0.11 & 10.46 & 1.50 \\
\hline & II & 139.40 & 0.26 & 36.24 & 5.20 \\
\hline & III & 836.40 & 0.17 & 142.19 & 20.40 \\
\hline & IV & 1118.87 & 0.38 & 425.17 & 61.00 \\
\hline & $\mathrm{V}$ & 1036.79 & 0.08 & 82.94 & 11.90 \\
\hline Total & & & 1 & 697.00 & 100 \\
\hline \multirow[t]{5}{*}{$48 \mathrm{~h}$} & I & 17.50 & 0.08 & 1.40 & 0.40 \\
\hline & II & 448.82 & 0.17 & 76.30 & 21.80 \\
\hline & III & 397.73 & 0.11 & 43.75 & 12.50 \\
\hline & IV & 358.29 & 0.38 & 136.15 & 38.90 \\
\hline & $\mathrm{V}$ & 355.38 & 0.26 & 92.40 & 26.40 \\
\hline Total & & & 1 & 350.00 & 100 \\
\hline \multirow[t]{5}{*}{$192 \mathrm{~h}$} & I & 16.55 & 0.08 & 1.32 & 0.40 \\
\hline & II & 175.24 & 0.17 & 29.79 & 9.00 \\
\hline & III & 385.16 & 0.11 & 42.37 & 12.80 \\
\hline & IV & 397.20 & 0.38 & 150.94 & 45.60 \\
\hline & $\mathrm{V}$ & 409.93 & 0.26 & 106.58 & 32.20 \\
\hline Total & & & 1 & 331.00 & 100 \\
\hline \multirow[t]{5}{*}{$240 \mathrm{~h}$} & I & 173.81 & 0.08 & 13.90 & 2.70 \\
\hline & II & 596.21 & 0.26 & 155.01 & 30.10 \\
\hline & III & 238.77 & 0.11 & 26.26 & 5.10 \\
\hline & IV & 636.97 & 0.38 & 242.05 & 47.00 \\
\hline & $\mathrm{V}$ & 457.44 & 0.17 & 77.76 & 15.10 \\
\hline Total & & & 1 & 514.98 & 100 \\
\hline \multirow{5}{*}{$312 \mathrm{~h}$} & I & 201.56 & 0.08 & 16.12 & 2.50 \\
\hline & II & 707.02 & 0.26 & 183.83 & 28.50 \\
\hline & III & 345.95 & 0.11 & 38.05 & 5.90 \\
\hline & IV & 833.41 & 0.38 & 316.70 & 49.10 \\
\hline & $\mathrm{V}$ & 531.18 & 0.17 & 90.30 & 14.00 \\
\hline Total & & & 1 & 645.00 & 100 \\
\hline \multirow[t]{5}{*}{$600 \mathrm{~h}$} & I & 1065.86 & 0.11 & 117.24 & 17.90 \\
\hline & II & 506.37 & 0.26 & 131.66 & 20.10 \\
\hline & III & 196.50 & 0.17 & 33.41 & 5.10 \\
\hline & IV & 868.74 & 0.38 & 330.12 & 50.40 \\
\hline & $\mathrm{V}$ & 532.19 & 0.08 & 42.58 & 6.50 \\
\hline Total & & & 1 & 655.01 & 100 \\
\hline
\end{tabular}


Table 4: Comparison table of DOM Types with different methods of identification

\begin{tabular}{llllll} 
& & \multicolumn{2}{l}{ TMFRI } & IMFRI \\
Time (h) & 3DEEMS & Types of identification & Agreement degree & Typesof identification & Agreement degree \\
\hline 0 & Region II and IV & Region IV and V & 0.5 & Region III and IV & 0.5 \\
48 & Region IV and V & Region II and III & 0 & Region IV and V & 1 \\
192 & Region IV and V & Region IV and V & 1 & Region IV and V & 1 \\
240 & Region II and IV & Region II and IV & 1 & Region II and IV & 1 \\
312 & Region II and IV & Region II and IV & 1 & Region II and IV & 1 \\
600 & Region II and IV & Region I and IV & 0.5 & Region II and IV & 1 \\
\hline
\end{tabular}

Notes: "0" stands for totally inconsistent agreement; " 0.5 " stands for partly agreement; " 1 " stands for complete agreement.

From Table 4, compared with the identification results of the TMFRI and 3DEEMS, the results are in complete agreement at time nodes $192 \mathrm{~h}, 240 \mathrm{~h}$ and 312 $\mathrm{h}$, while the results at $0 \mathrm{~h}$ and $600 \mathrm{~h}$ are only partially in agreement and the results at $48 \mathrm{~h}$ are completely different. The identification types of DOM are quite different from the TMFRI and 3DEEMS. Compared the results with the IMFRI and 3DEEMS, the results are all in complete agreement except that at $0 \mathrm{~h}$ and the identification types of DOM are mostly the same from the IMFRI and 3DEEMS.

According to the studies above, TMFRI simply makes use of the integral value to characterize the fluorescence spectra quantity in each section. The DOM types that it identifies are quite different from that of 3DEEMS, with an accuracy of $50 \%$, which makes it difficult to identify the features of the DOM transformation. The IMFRI can confirm the weight by wholly considering the location of the peak value of the 3DEEMS and the effect among the five sections, calculating the fluorescence spectra quantity in each section. The DOM types identified by this method are well matched with the results from 3DEEMS, with an accuracy of $83.33 \%$, so this method can be used to identify the transformation features of DOM.

\section{Conclusion}

1. The main types of DOM in leachate from 3DEEMS are: Tryptophan and soluble microbial metabolites at $0 \mathrm{~h}$; soluble microbial metabolites and humic acids at $48 \mathrm{~h}$ and $192 \mathrm{~h}$; and tryptophan and soluble microbial metabolites at $240 \mathrm{~h}, 312 \mathrm{~h}$ and $600 \mathrm{~h}$

2. The recognition types of DOM with the TMFRI are quite different from that from the 3DEEMS, with an accuracy of $50 \%$, which makes it difficult to identify the transformation features of DOM

3. The DOM types that the IMFRI identified have a higher agreement that those identified the 3DEEMS, with an accuracy of $83.33 \%$, which can be used to identify the transformation features of DOM

\section{Acknowledgment}

This work was financially supported by the National Natural Science Foundation of China (Grant 41672240), Henan Province's Technological Innovation Team of
Colleges and Universities (Grant 15IRTSTHN027), Innovation Scientists and Technicians Troop Construction Projects of Henan Province (Grant CXTD2016053), Fundamental Research Funds for the Universities of Henan Province (NSFRF1611), Scientists and Technicians Projects of Henan Province (Grant 172107000004).

\section{Author's Contributions}

Zhang Jianguo: Designed the research plan and organized the study.

Wang Xinyi: Contributed to the writing of the manuscript.

Liu Xiaoman: Participated in all experiments, coordinated the data-analysis.

Li Jianlin: Coordinated the mouse work.

Guo Jianwei: Collated data and analyzed results.

Zhang Bo: Contributed to the writing of the manuscript.

\section{Ethics}

The authors declare their responsibility for any ethical issues that may arise after the publication of this manuscript.

\section{Conflict of Interest}

The authors declare that they have no competing interests. The corresponding author affirms that all of the authors have read and approved the manuscript.

\section{References}

Buffle, J. and G.G. Leppard, 1995. Characterization of aquatic colloids and macromolecules. 2. Key role of physical structures on analytical results. Environ. Sci. Technol., 29: 2176-2184.

DOI: $10.1021 / \mathrm{es} 00009 \mathrm{a} 005$

Christman, R.F. and E.T. Gjessing, 1983. Aquatic and terrestrial humicmaterials [M]. Ann Arbor Science: Ann Arbor, Ml.

Coble, P.G., S.A. Green, N.V. Blough and R.B. Gagosian, 1990. Characterization of dissolved organic matter in the Black sea by fluorescence spectroscopy. Nature, 348: 432-435. DOI: $10.1038 / 348432 \mathrm{a} 0$ 
Cui, J., D. Yuan, X. Guo, L. He and J. He et al., 2016. Characterization of dissolved organic matter in lake baiyangdian using spectroscopic techniques and multivariate statistical analysis. CLEAN-Soil Air Water, 44: 1444-1452.

DOI: $10.1002 /$ clen.201500887

Ghabbour, E.A. and G. Davies, 2001. Humic Substances: Structures, Models and Functions. 1st Edn., The Royal Society of Chemistry, Cambridge, ISBN-10: 0854048111, pp: 387.

He, X.S., B.D. Xi, R.T. Gao, L. Wang and Y. Ma et al., 2015. Using fluorescence spectroscopy coupled with chemometric analysis to investigate the origin, composition and dynamics of dissolved organic matter in leachate-polluted groundwater. Environ. Sci. Pollut. Res., 22: 8499-8506.

DOI: $10.1007 / \mathrm{s} 11356-014-4029-7$

He, X.S., B.D. Xi, Z.M. Wei, Y.H. Jiang and Y. Yang et al., 2011. Fluorescence excitation-emission matrix spectroscopy with regional integration analysis for characterizing composition and transformation of dissolved organic matter in landfill leachates. J. Hazardous Mater., 190: 293-299.

DOI: 10.1016/j.jhazmat.2011.03.047

Jiang, X.P., J. Yao and H. Zhang, 2015. Evaluation of dissolved organic matter removal efficiency by different plants based on fluorescence regional integration.

Johs, A., V.A. Eller, T.L. Mehlhorn, S.C. Brooks and D.P. Harper et al., 2019. Dissolved organic matter reduces the effectiveness of sorbents for mercury removal. Sci. Total Environ., 10: 410-416.

DOI: 10.1016/j.scitotenv.2019.07.001

Leenheer, J.A. and J.P. Croué, 2003. Characterizing aquatic dissolved organic matter. Environ. Sci. Technol., 37: 18A-26A. DOI: 10.1021/es032333c

Lei, H.J., H.W. Pan, Y.P. Han, X. Liu and J.X. Xu 2015. Using three-dimensional fluorescence spectrum technology to analyze the effects of natural dissolved organic matter on the pesticide residues in the soil. Spectroscopy Spectral Anal., 35: 1926-1931.

DOI: 10.3964/j.issn.1000-0593(2015)07-1926-07

Li, G., S. Khan, M. Ibrahim, T.R. Sun and J.F. Tang et al., 2018. Biochars induced modification of Dissolved Organic Matter (DOM) in soil and its impact on mobility and bioaccumulation of arsenic and cadmium. J. Hazardous Mater., 15: 100-108. DOI: 10.1016/j.jhazmat.2018.01.031

Maximiliano, B., Z. Graciela and A. Marcelo, 2009. Effect of $\mathrm{pH}$, anions and cations on the dissolution kinetics of humic acid particles. Colloids Surfaces, 347: 180-186. DOI: 10.1016/j.colsurfa.2009.04.003
Pollo, F.J.P., 1993. Evolution of Organic Matter in Some Soils Under Shifting Cultivation Practices in Burkina Faso. In: Soil Organic Mater Dynamics and Sustainability of Tropical Agriculture [M], Mulongoy, K. and R. Merckx (Eds.), Awiley-Saycc Co-Publication, pp: 109-120.

Porcal, P. and J. Kopáček, 2018. Photochemical degradation of dissolved organic matter reduces the availability of phosphorus for aquatic primary producers. Chemosphere, 193: 1018-1026. DOI: $10.1016 /$ j.chemosphere.2017.11.140

Waksman, S.A., 1938. Humus-Origin, Chemical: Composition and Important in Nature[M]. 2nd Edn., Williaiiis and Wilkilis, Baliillore.

Wang, X.Y., T.T. Wang, Q. Wang, X.M. Liu and R.Z. Li et al., 2017. Evaluation of floor water inrush based on fractal theory and an improved analytic hierarchy process. Mine Water Environ., 36: 87-95.

DOI: $10.1007 / \mathrm{s} 10230-016-0407-3$

Chen, W., P. Westerhoff, J.A. Leenheer and K. Booksh, 2003. Fluorescence excitation-emission matrix regional integration to quantify spectra for dissolved organic matter. Environ. Sci. Technol., 37: 5701-5710. DOI: 10.1021/es034354c

Xu, J., X.Q. Bian and Z.H. Chang, 2007. Optimizing replanning decisions for autonomous underwater vehicles through an improved analytical hierarchy process. J. Harbin Eng. Univ., 28: 403-334.

Zhao, J., B.D. Xi, Q.G. Xu, Y. Zhao and Z.M. Wei et al., 2013. Studies on fluorescence spectral characteristics of Fulvic Acid (FA) from xingkai lake sediments. Spectroscopy Spectral Anal., 33: 1824-1828. DOI: 10.3964/j.issn.1000-0593(2013)07-1824-05

Zhou, Q., X. Li, Y. Lin, C. Yang and W. Tang et al., 2019. Effects of copper ions on removal of nutrients from swine wastewater and on release of dissolved organic matter in duckweed systems. Water Res., 1: 171-181. DOI: 10.1016/j.watres.2019.04.036

Zhou, Y.M., Q. Zhang and H.X. Tang, 2010. Sorption behavior of polycyclic aromatic hydrocarbons onto humic acid particulates. Acta Scientiae Circumstantiae, 30: 1564-1571.

Zhu, W.H., T.L. Huang and Y.N. Zhang, 2010. The influence of the redox conditions on the ThreeDimensional Excitation-Emission Matrix (3DEEM) fluorescence spectroscopy of the Dissolved Organic Matter (DOM) in the overlying water. Spectroscopy Spectral Anal., 32: 3272-3276.

DOI: 10.3964/j.issn.1000-0593(2010)12-3272-05 